\title{
A Helmet Cueing System Based Firing Control for Anti-Aircraft Gun Prototype
}

\author{
A.M. Solomon ${ }^{1}$, M.B. Asrat ${ }^{2 *}$ and S. Ramasamy ${ }^{2}$ \\ ${ }^{1}$ Department of Mechatronics Engineering, Addis Ababa Science and Technology University, \\ Addis Ababa, Ethiopia \\ ${ }^{2}$ Artificial Intelligence and Robotics Centre of Excellence, Addis Ababa Science and Technology \\ University, Addis Ababa, Ethiopia
}

The manuscript was received on 19 November 2019 and was accepted after revision for publication as research paper on 26 February 2021.

\begin{abstract}
:
This article deals with a firing control system which has been developed for Anti-aircraft gun prototype by integrating video processor with a helmet-mounted cueing system. The system consists of a camera and an inertial measuring unit, which continuously reports the gunner's head position for the microcontroller. The system is deployed on a prototype hardware and tested using experimentation by varying the target range and the controller parameters. The evaluation results show an overall system response of $1.75 \mathrm{~s}$, and approximately $82 \%$ of accuracy of detection. Moreover, the deployed stepper motors have given $95 \%$ of accuracy in input waveform tracking, while the settling time of $0.052 \mathrm{~s}$ is found for a correction deviation of $100^{\circ}$.
\end{abstract}

\section{Keywords:}

anti-aircraft gun, firing control, helmet cueing, image processing, PID

\section{Introduction}

Fire control system is a mechanism of firing on an enemy target by creating a proper offset angle between the muzzle fire direction and sightline of a target which can be moving or stationary. This offset angle is referred to as predication angle. The three necessary steps to formulate the prediction angle decision are (1) collecting the relevant inputs about the target, (2) computing the required gun orientation components (azimuth and elevation angles), and (3) implementing the above two elements on the control system to orient the gun precisely towards the target. In some cases, human cannoneer is considered as part of the firing control system [1].

\footnotetext{
* Corresponding author: Artificial Intelligence and Robotics Centre of Excellence, Addis Ababa Science and Technology University, Addis Ababa, Ethiopia. Phone: +251911538342, E-mail: asrat.mulatu@aastu.edu.et
} 
The use of infrared imaging and video as a targeting feature in fire control is furnished in contemporary weapons. The video signal holds the selected target's information (moving or stationary) and its background scene. Firing computers utilize video processing algorithms to differentiate a target from its background that helps to discover the target current position. The target position signal is used as a drive command for actuator motors to position the gun barrel tip towards the target location [1].

An integrated helmet-mounted cueing system, a.k.a. helmet tracking system, is a technology used mainly in contemporary combat aircraft cockpits, which accurately tracks and provides information about the pilot's head orientation and movements to the flight computer (in the case of fighting jets). The cueing process carried out with the help of sensors that are mounted on the integrated helmet of the pilot, generally, has good accuracy and negligible effect on the helmet with respect to size and load [2].

Varieties of helmet (cueing) tracking techniques are available such as acoustic, optical, electromechanical and inertial trackers [2]. In recent days, a hybrid design of trackers is available, which is a merger of optical and inertial techniques to increase the tracking accuracy [3].

\section{Mathematical Representation}

\subsection{Gun Kinematics in Lagrangian Mechanics}

Anti-aircraft guns has two degrees of freedom motion, namely azimuth (yaw) and elevation (pitch) in which the former spans from $0^{\circ}$ to $360^{\circ}$ and the latter can elevate from $0^{\circ}$ to $90^{\circ}$. These two motions can help the weapon to cover a spherical working envelop enabling it to attack an enemy target aircraft in any direction [4]. Fig. 1 shows a typical Anti-Aircraft Gun (AAG) in firing position.

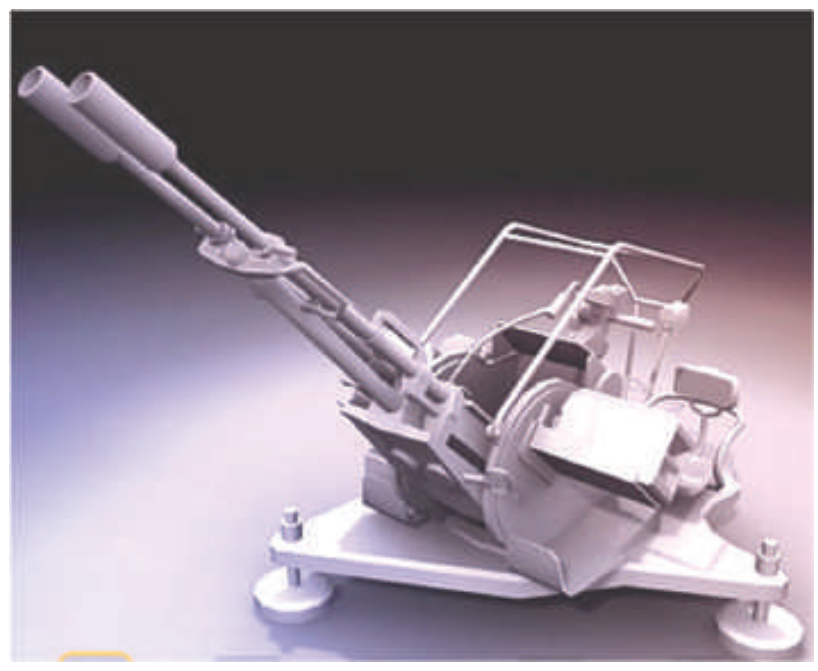

Fig. 1 Antiaircraft gun [5]

From the simplified representation of the gun, on which its original dimensions are indicated, forward and backward kinematics can be calculated from the gun overall dimensions. The angles found from the kinematics equation are used as input to develop lead angle calculation of the gun. 


\subsection{Forward Kinematics}

The forward kinematics is calculated to determine the position and orientation of the gun muzzle by using joint angles and dimensions [6].

In Figs 2 and 3 below, elevation angle $\alpha$, muzzle length $L 1$, distance between gun rotation center and muzzle joint $L 2$ and the height of the gun center from the $X$-axis $K$, position of muzzle tip in $Z$ direction $Z B$ and position of gun in $X$ direction $X B$ are indicated on the side view ( $Z-X$ coordinate) of the weapon.

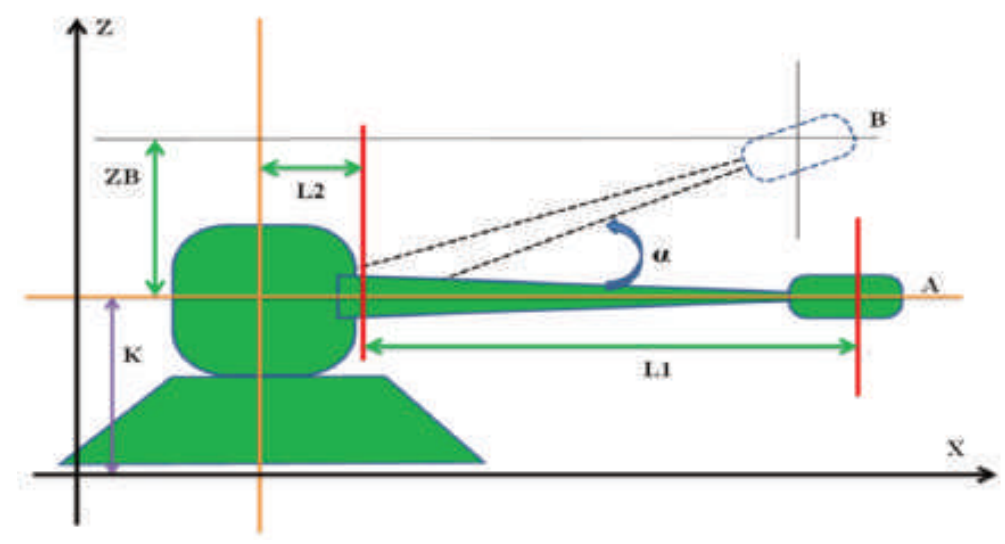

Fig. 2 Anti-air craft gun orientation: side view

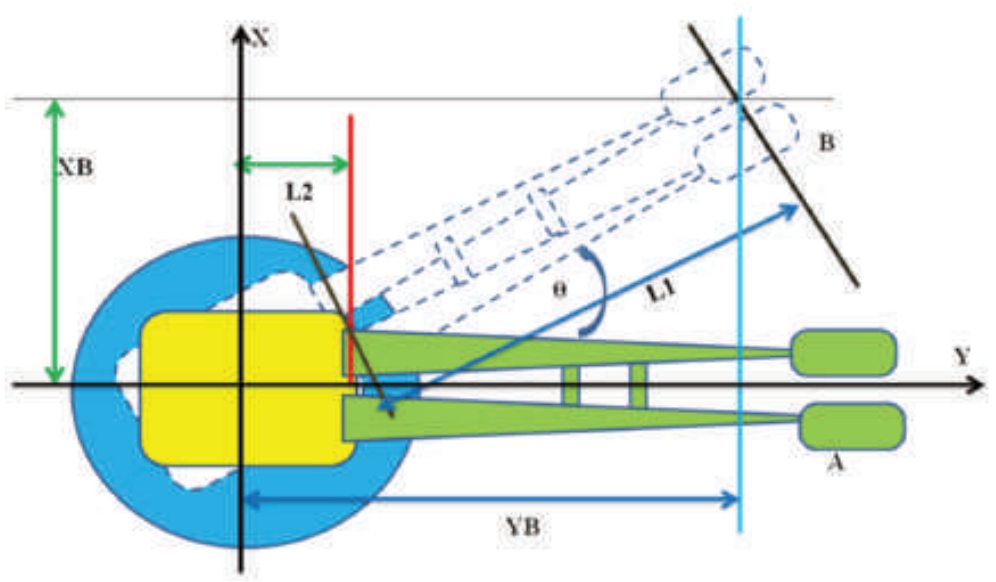

Fig. 3 Anti-air craft gun orientation: top view

From the above figures, $(X-Z$ axis $)$ muzzle tip position is determined in the $Z$ direction and $X$ direction, respectively, as in Eq. (1):

$$
\begin{aligned}
& Z B=K+L_{1} \sin \alpha \\
& X B=\left(L_{2}+L_{1} \cos \alpha\right) \sin \theta
\end{aligned}
$$

Similarly, the muzzle position in the $Y$ direction is given by:

$$
Y B=\left(L_{2}+L_{1} \cos \alpha\right) \cos \theta
$$




\subsection{Backward Kinematics}

The two joint angles $\theta$ and $\alpha$ can be expressed in terms of link length values which are used to determine the orientation of the gun from the current gun position as:

$$
\begin{aligned}
\sin \alpha & =\frac{Z B-K}{L_{1}} \\
\alpha & =\sin ^{-1} \frac{Z B-K}{L_{1}}
\end{aligned}
$$

Similarly, to find $\theta$ by using trigonometric rules

$$
\frac{\cos \theta}{\sin \theta}=\frac{Y B\left(L_{1}+\cos \alpha\right)}{X B\left(L_{1}+\cos \alpha\right)}
$$

Therefore,

$$
\theta=\tan ^{-1} \frac{Y B}{X B}
$$

\section{Lead Angle Calculation}

The basic gunnery problem in light with anti-aircraft weapons is to steer the gun to displace its barrel ahead of the selected target [3]. The displacement angle used to rotate the gun to point ahead of the target is the lead angle [7]. Angular references of bearing and elevation are indicated in 3-dimensional coordinates (Fig. 4), which is considered here to find the value of $t$ in which the target flies from $A$ to $B$ with a straight-line trajectory, where the gun is set on the origin of the coordinate. The values of $e$ and $b$ denote the elevation and bearing angles to hit the target, respectively [8].

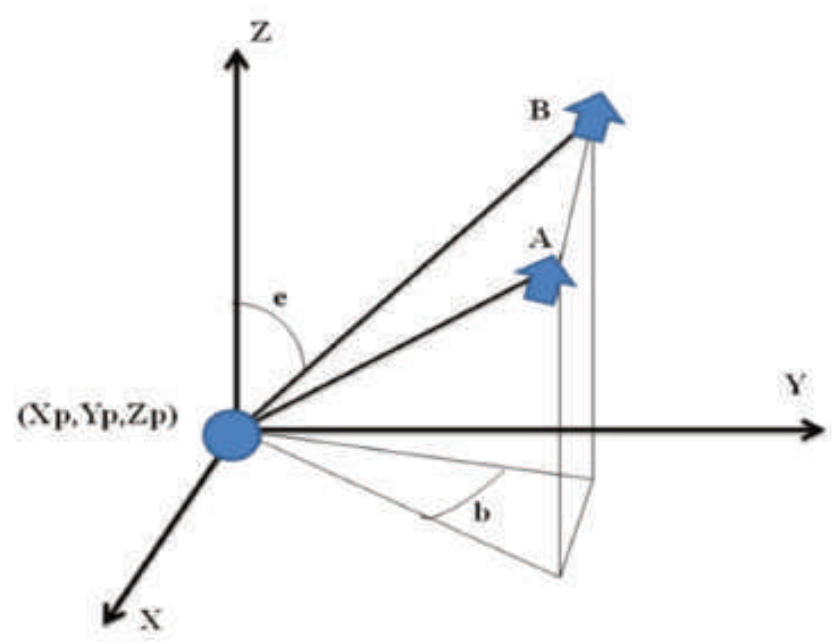

Fig. 4 Anti-aircraft gun 3D coordinate frame

To ensure the collision between the fired bullets from the weapon and the flying aircraft target, the equation of motion of both the projectile and the target in a 3-dimensional axis is equated as in Eq. (5) [8]. 


$$
\left.\begin{array}{c}
X_{t}+V_{t x} t+\frac{1}{2} A_{t x} t^{2}=X_{\mathrm{p}}+V_{\mathrm{p} x} t-\frac{1}{2} D_{\mathrm{pav} x} t^{2} \\
Y_{t}+V_{t y} t+\frac{1}{2} A_{t x} t^{2}=Y_{\mathrm{p}}+V_{\mathrm{p} y} t-\frac{1}{2} D_{\mathrm{pav} y} t^{2} \\
Z_{t}+V_{t z} t+\frac{1}{2} A_{t x} t^{2}=Z_{\mathrm{p}}+V_{\mathrm{p} z} t-\frac{1}{2} D_{\mathrm{pav} z} t^{2}
\end{array}\right\}
$$

$V_{t x^{\prime}} V_{t y}, V_{t z}$ are the target's initial velocities and $D_{\text {pav } x}, D_{\text {pavy }}, D_{\text {pavz }}$ represent the projectiles average decelerations. The main interest is to correctly find the specific root which is used to estimate the guns angular orientation among the possible roots.

From Fig. 5 below resolving $e$ with cosine gives the deceleration due to gravity where the target is initially located at the point $A$. Therefore, $d_{1}$ becomes:

$$
d_{1}=K t_{1}-\frac{1}{2} D_{\text {pav }} t_{1}^{2}-\frac{1}{2} t_{1}^{2} g \cos \left(90^{\circ}-e_{1}\right)
$$

where $t_{1}$ (time of flight) can be determined from the above Eq. (6).

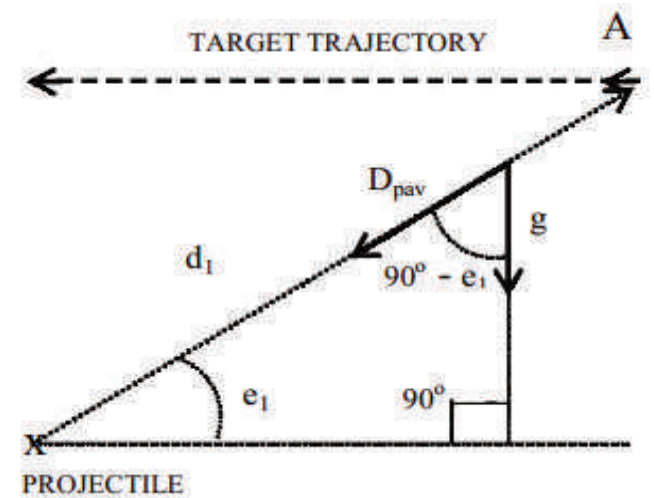

Fig. 5 Forces on moving projectile

Because of the high muzzle velocity $K$ of modern anti-aircraft gun, the gravity value can be ignored because it is much smaller than $K$ [8].

$$
D_{\text {pav }} t_{1}^{2}-2 K t_{1}+2 d_{1}=0
$$

After solving the quadratic equation in Eq. (7), the value of $t$ can be found by substituting $K, D_{\text {pav }}$ and $d_{1}$ values.

The values of elevation $e$ and bearing $b$ can be calculated as:

$$
\left.\begin{array}{c}
e_{p}=\frac{Z_{t}-Z_{\mathrm{p}}+V_{t z}+\frac{1}{2} A_{t z} t^{2}+\frac{1}{2} g t^{2}}{k t-\frac{1}{2} D_{\mathrm{pav} z} t^{2}} \\
b_{p}=\sin ^{-1} \frac{Y_{t}-Y_{\mathrm{p}}+V_{t y} t+\frac{1}{2} A_{t y} t^{2}}{\left(k t-\frac{1}{2} D_{\mathrm{pav} z} t^{2}\right) \cos e_{\mathrm{p}}}
\end{array}\right\}
$$

In this work, MATLAB has been used to generate the different time values by varying the target speed and position. 


\section{Video Processing Algorithm}

For the developed firing control system, video processing is used to detect and track the flying target using camera as a visual sensor. The process begins with object detection from the input video frames followed by classifying the target of interest and the actual object tracking proceeds. Fig. 6 depicts the steps taken in the video processing technique [9].

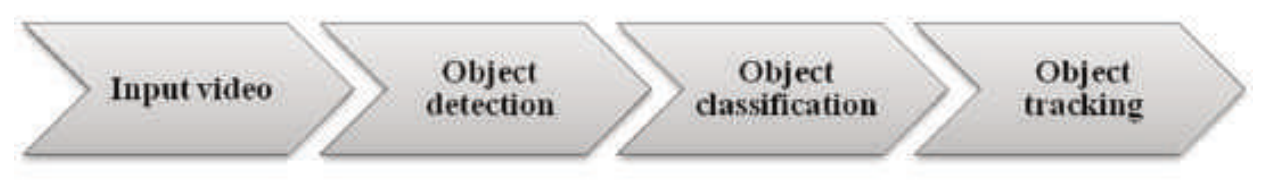

Fig. 6 Steps in video processing for target tracking

\subsection{Object Detection Algorithms}

There are three different methods used for object detection namely [9, 10]:

- frame difference (FD),

- background subtraction,

- optical flow method (OF).

Frame difference method calculates the difference between two consecutive image frame pixels to recognize a target allowing a moving image to be detected easily [9]. The background subtraction involves the comparison of current video frame with the previously determined background model [10]. In optical flow method, an object is detected by calculating the difference between the image-frame motions which are taken in time $t$, and $t+\mathrm{d} t$ at each and every pixel [10].

\subsection{Main Steps of Detection Process}

The input video signal contains a region of interest in which the target and its background are visible. Every two consecutive frames are needed to detect a moving object to find the difference between them. Fig. 7 shows the object detection algorithm used in this research. Converting from RGB (Red-Green-Blue) to greyscale is the second step in the object detection process. Grayscale images are used to simplify the image processing and reduce computational time [11]. A frame is a combination of different pixel color values represented only with black and white color combinations in which the three RGB values of pixels are replaced by a single value [12].

As indicated in Fig.7, for frame differencing algorithm, two consecutive image (previous and reference) frames are needed to detect an object by finding their differences. It is a simple algorithm in terms of calculation having good adaptability on a variety of backgrounds [9]. Moreover, it is popular due to its better performance in real-time applications [13, 14]. Mathematically, it can be expressed [14] as:

$$
D_{k}=F_{k}-F_{k-1}
$$

where $D_{k}$ is the difference frame, $F_{k}$ is the $k^{\text {th }}$ image frame and $F_{k-1}$ is the previous frame. 


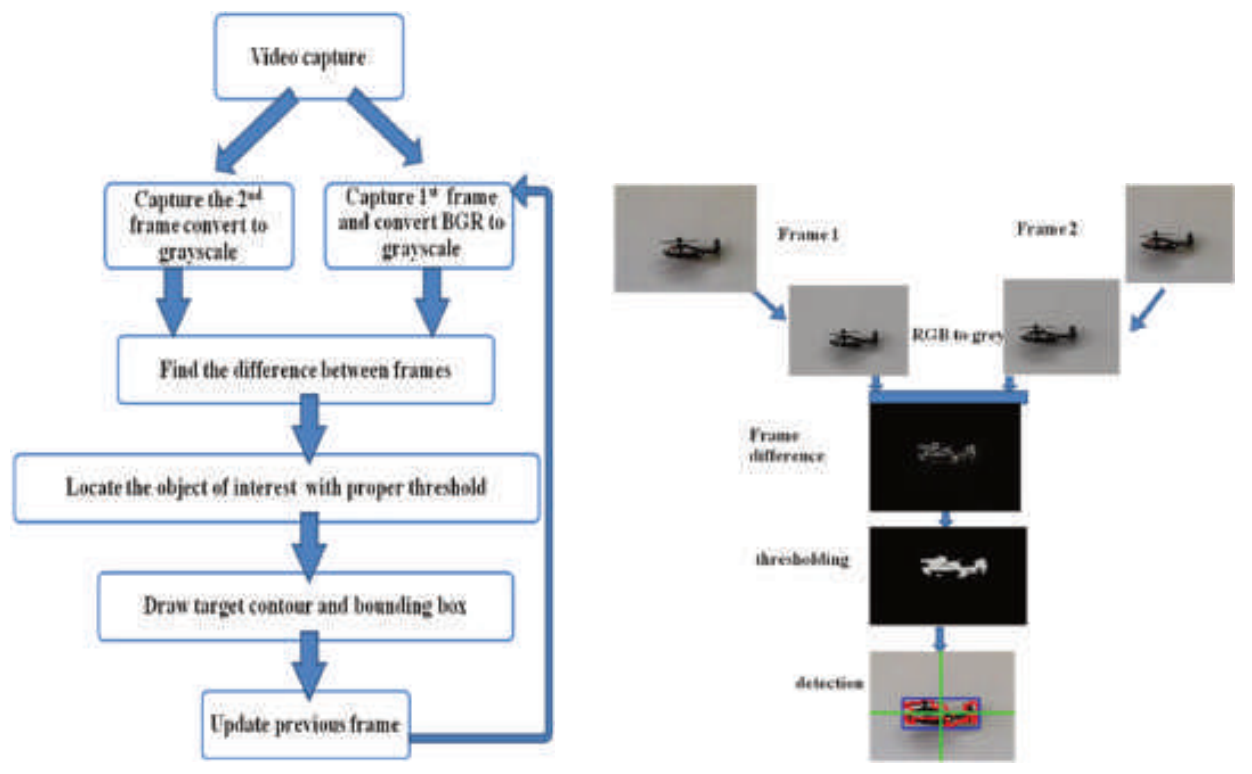

Fig. 7 Frame difference algorithm

\subsection{Extraction of Target Contour}

Python's CV2.findcontour() function is used to find the contour of the extracted target as shown in Fig. 8. This function uses the Suzuki-Kasmi algorithm to bind the desired target binary image where a white blob (foreground target) is used to determine its contour by connecting each points and curves of the feature boundary [15].
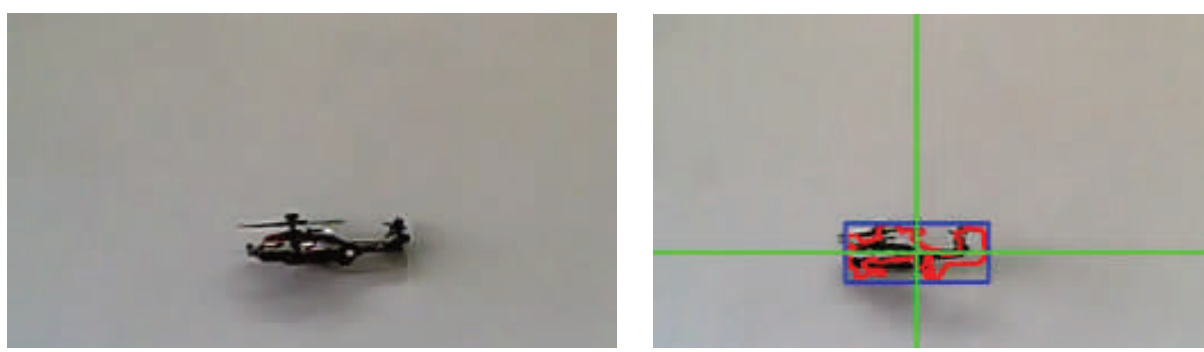

Fig. 8 Object contour

\subsection{Moving Object Tracking}

As stated in [16], among various moving target tracking techniques, the centroid tracking method is the better algorithm to track a fast-moving aerial target, specifically an aircraft flying in the sky. This technique can track a target even when the actuator pan tilt mechanism cannot follow the target because of high acceleration [16]. To find the center of the contour, a bounding rectangle has to be firstly drawn on the object feature boundary, namely minimum bounding box, where it contains all points of the shape contour [16].

Generally, as indicated in Fig. 9, the center can be calculated by dividing the height and width of the bounding rectangle by two. 


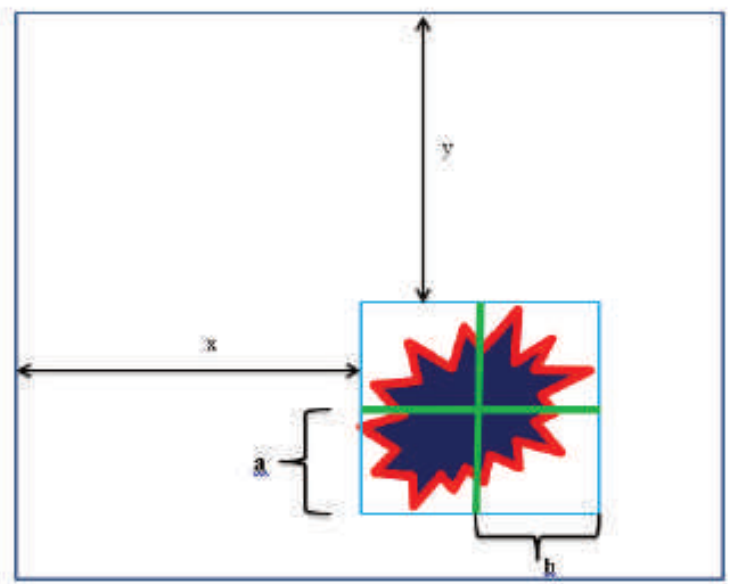

Fig. 9 Target object in single frame with its contour

In addition, the distance from the center of the object to the edges of the image frame can be found using Eq. (10). This in turn is used to position the azimuth and elevation motors of the gun platform to the aircraft's central position with respect to the initial position.

$$
\left.\begin{array}{l}
X=x+\frac{\text { width of the rectangle }}{2} \\
Y=y+\frac{\text { height of the rectangle }}{2}
\end{array}\right\}
$$

The gun uses these signals as input during firing control calculations.

\section{Prototype Development and Experimental Setup}

Anti-aircraft gun prototype is constructed to carry out further study and experimentation on the overall proposed system and its major components including image processing, helmet cueing and controller subsystems (Fig. 10). The hardware consists of a wooden gun platform with a stationary base above which the gun is rotating.

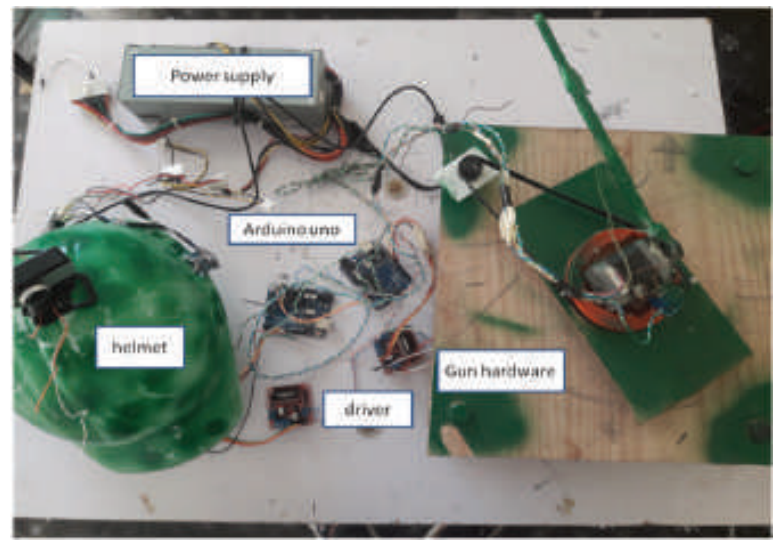

Fig. 10 Components used in prototype development 
As shown in Fig. 11, electrical components are also integrated in the prototype system including two stepper motors, for azimuth and gun rotation, and two-bridge driver boards, for each motor. The controller is implemented using Arduino microcontroller which is backed by a power supply unit that delivers a constant and regulated power for the motors. The Arduino microcontroller controls the overall system too.

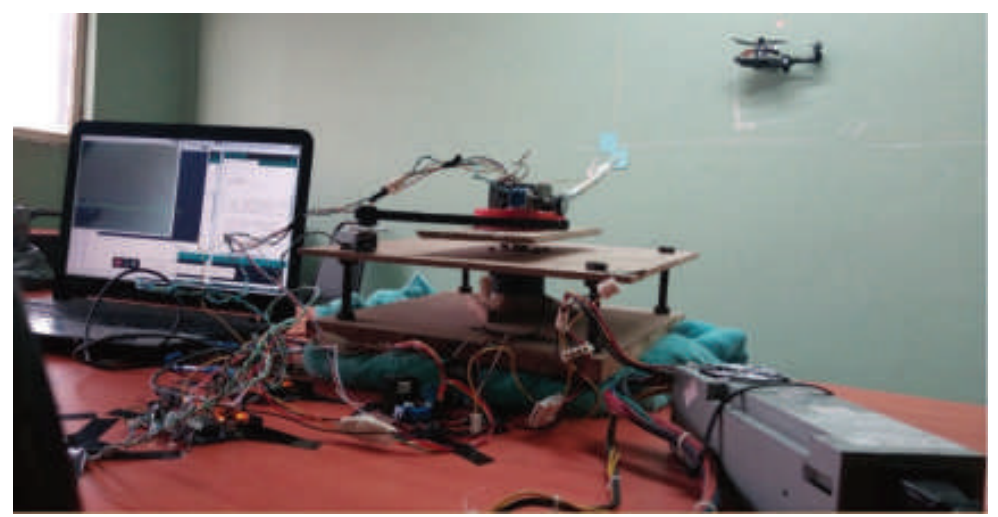

Fig. 11 Prototype gun hardware with model aircraft

\section{Experiments and Results}

\subsection{PI Controller}

During experimentation, manual tuning has been used to find the optimal values of overshoot and response time of the motors. Fig. 12 presents the responses of the motors for different values of $\mathrm{Ki}$. As plotted in Fig. 12a from the tested $K \mathrm{i}$ values, $K \mathrm{i}=0.25$ shows a smaller overshoot of $18 \%$ and slower settling time of $0.080 \mathrm{~s}$.

The response of the motors for the maximum value of integral coefficient of $K i=1.08$ is indicated in Fig. 12b. From the graph, higher overshoot of $40 \%$ and slightly faster response time of $0.050 \mathrm{~s}$ were observed.

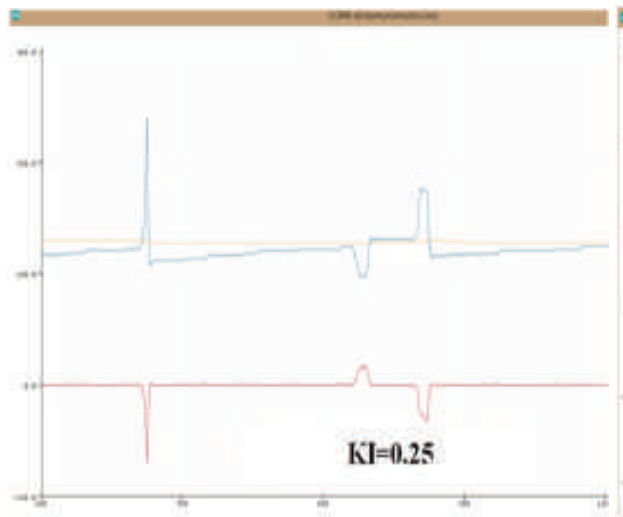

a)

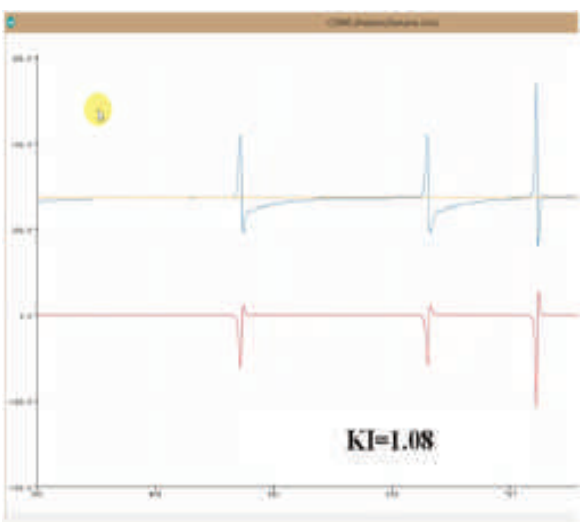

b)

Fig. 12 Motor response @ Ki = 0.25 and Ki = 1.08 (i.e. orange - input signal, blue - output signal, and red-control signal) 
By comparing all of the tested integral coefficient values, $K \mathrm{i}=0.87$ was found to be optimal. From the plot of Fig. 13, one can observe that $24 \%$ of overshoot with $0.052 \mathrm{~s}$ of response time is needed to achieve a random error of $100^{\circ}$.

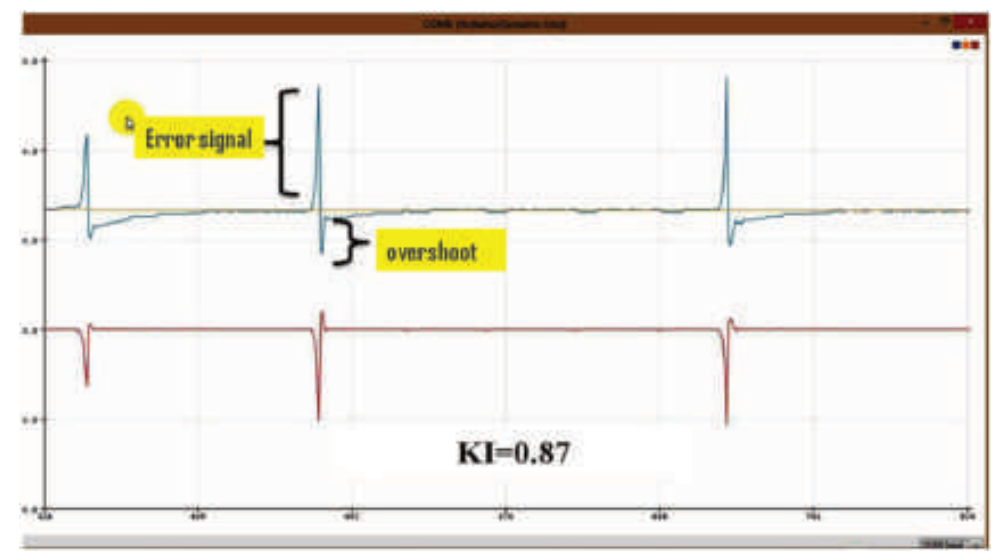

Fig. 13 Motor response @ Ki = 0.87 (i.e. orange -input signal, blue - output signal, and red-control signal)

\subsection{Target Detection}

The target detection algorithms, namely frame difference and optical flow methods, are tested for detection performance with three different backgrounds. The first background is clear sky background as shown in Fig. 14.

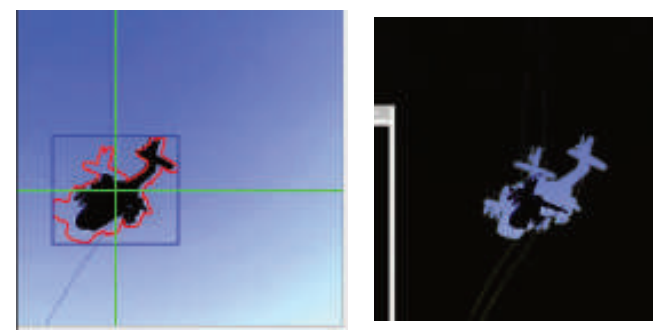

Fig. 14 Frame difference detection in clear sky

The second experiment of detection was carried out considering cloudy sky. The bright clouds appear slightly in frame difference detection technique, but because of the relative motion, the target appears to be brighter than the background as shown in Fig. 15.

The last experiment of detection was carried by considering a slightly complex background. Frame difference detects the target when it is fast moving relative to the background motion (Fig. 16).

\subsection{Tracking Performance}

The tracking performance of the gun was tested by continuously moving a mini target aircraft and recording the gun's tip points in every $2 \mathrm{~s}$. This time is needed for the gun to compute and respond to the target's position change. 

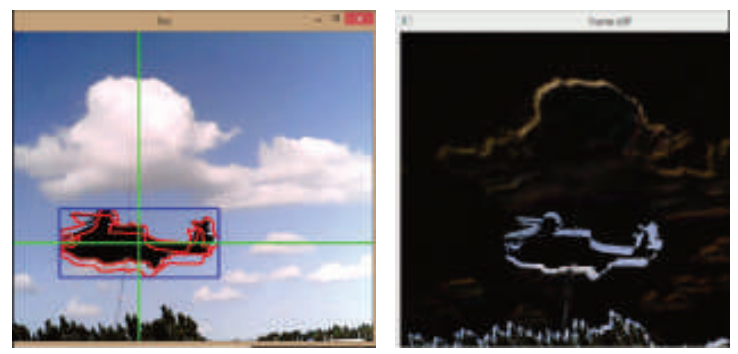

Fig. 15 Frame difference detection in cloudy sky

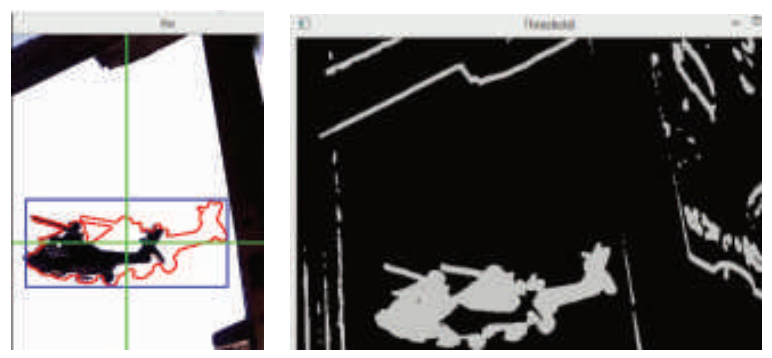

Fig. 16 Frame difference detection in a complex background

A green-colored background is used to see where the gun is pointing by the help of gun pointer. The distance of the target was tested for 1,2 , and $4 \mathrm{~m}$ from the gun platform. The first experiment was carried out for a $4 \mathrm{~m}$ target range (Fig. 17). Out of the four frames, the gun is commanded to point at the top of the target, actually $0.5^{\circ}$ above the target, where for the first 3 frames, the response was correct (i.e. from right to left).

The next experiment was taken at the gun distance of $2 \mathrm{~m}$ from the target on which the hardware is commanded to point the head $\left(0.5^{\circ}\right.$ above and $1^{\circ}$ front $)$ of the gun from 8 consecutive frames where only at frame 2 an error was detected (Fig. 18).

The third experiment was conducted at a range of 1 meter of the target from the gun where it first commanded to point below the center of the target $\left(0.5^{\circ} \mathrm{s}\right)$. From the result it obtained, only frames number 8 and 9 show errors while the others are correct (Fig. 19).

All in all, three errors were detected during the tracking experiment. The first one is when the gun is pointing on unwanted target. The second one is when the gun loses the contour because of the fast moving target, and finally, the third is observed when a dark shadow was tracked as a target (see Fig. 20).

Tab. 1 presents the tracking accuracy of the proposed system which is calculated by dividing the frame errors by total frames.

Moreover, the results in the third experiment (Tab. 1) show that a slightly better result was obtained because of the motors used in the prototype have lower resolution (i.e. $\left.1.8^{\circ}\right)$. However, some deviation was observed when the target was far from the gun.

The errors detected in the experiment are very small in magnitude, which is a maximum of $0.5^{\circ}$ in deviation. However, this has a low effect on moving targets and on an average of $15 \mathrm{~m}$ long aircraft. It is believed that hitting a flying aircraft at any point results a sufficient damage. 


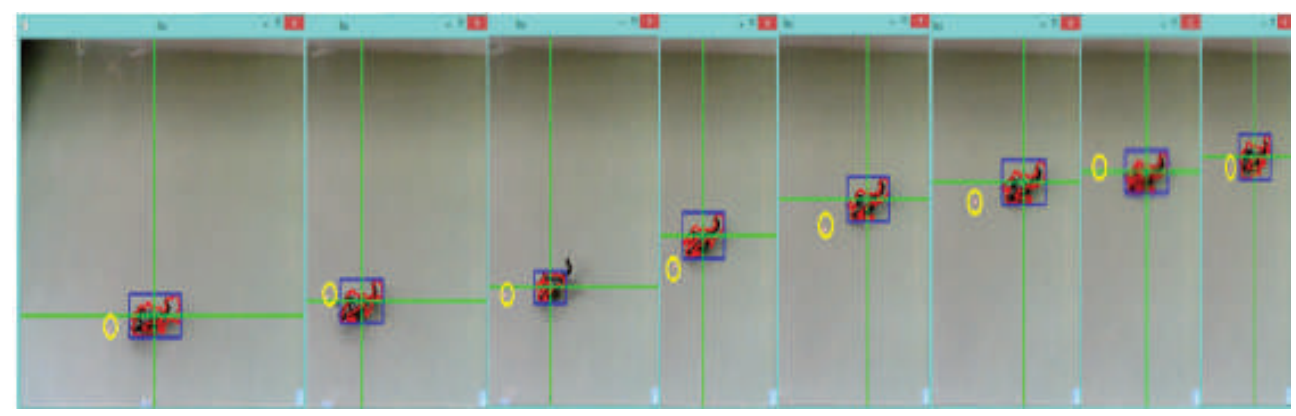

Fig. 17 Gun pointing ahead of the target body from $4 \mathrm{~m}$ range

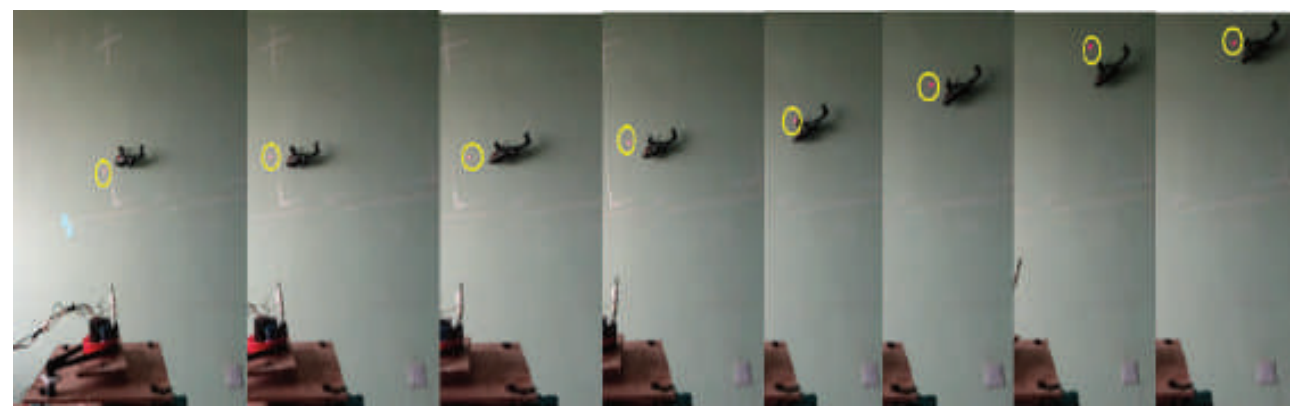

Fig. 18 Gun pointing ahead of the target body from $2 \mathrm{~m}$ range

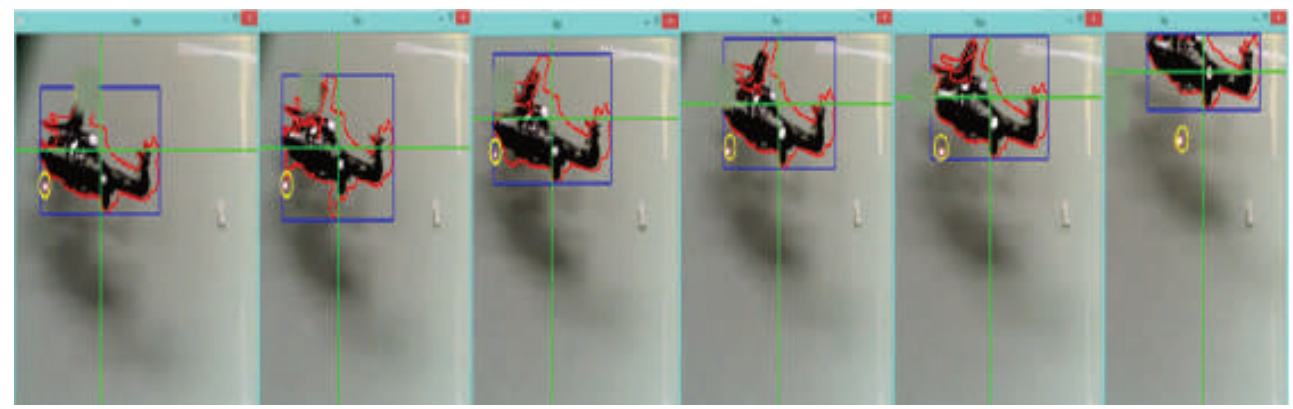

Fig. 19 Gun pointing ahead of the target body from $1 \mathrm{~m}$ range

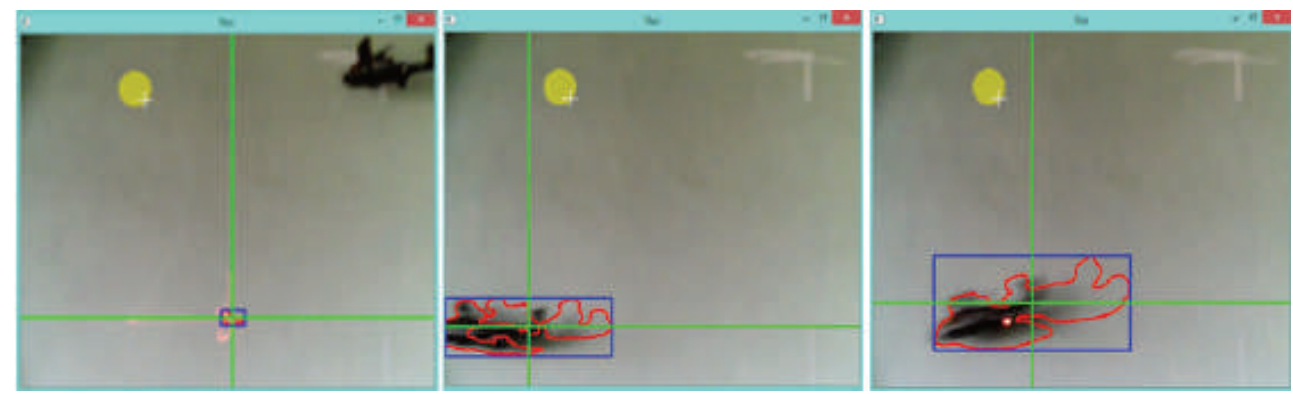

Fig. 20 Errors observed during tracking 
Tab. 1 Tracking accuracy of the proposed system

\begin{tabular}{|c|c|c|c|}
\hline \multirow{2}{*}{ Target Range } & \multicolumn{3}{|c|}{ Tracking Accuracy [\%] } \\
\cline { 2 - 4 } & Experiment 1 & Experiment 2 & Experiment 3 \\
\hline $4 \mathrm{~m}$ & 75 & 70 & 80 \\
\hline $2 \mathrm{~m}$ & 83 & 85 & 81 \\
\hline $1 \mathrm{~m}$ & 80 & 90 & 86 \\
\hline
\end{tabular}

Finally, the appropriate detection algorithm was selected by analyzing the experiment results where improvements in the gun firing control are achieved due to the aid of the helmet mounted cueing system. The advantage of the stepper motor is observed in terms of angular accuracy, faster response time, and holding torque characters.

Tab. 2 summarizes a comparative performance evaluation of the proposed system with previous works on gun motor controllers. The proposed system shows better performance in terms of response time and set point from other related works. And yet, its error indicates the need for further investigation in that regard.

\section{Conclusions}

This work proposed a helmet mounted cueing system for AAG prototype by integrating image processing system. Almost all previous works used a servo motor actuator for azimuth and elevation drive. However, in this work a stepper motor was used to take the advantage of its high-torque size ratio and the better position accuracy of the open-loop controller.

Tab. 2 Proposed system performance in comparison with other related works

\begin{tabular}{|c|c|c|}
\hline & Approach/method used & Performances \\
\hline 1 & $\begin{array}{l}\text { Sliding Mode Control of Target Tracking System } \\
\text { for Gun Turret Model with DC motor actuator [17] }\end{array}$ & $\begin{array}{l}400 \text { set point } \\
10 \% \text { error } \\
0.15 \text { s response time }\end{array}$ \\
\hline 2 & $\begin{array}{l}\text { PID control for Gun Turret Automatic Weapon } \\
\text { Control System with DC motor actuator [18] }\end{array}$ & $\begin{array}{l}220 \text { set point } \\
3.75 \% \text { overshoot } \\
0.382 \text { s response time }\end{array}$ \\
\hline 3 & $\begin{array}{l}\text { Coil-gun Turret Control System with PID control- } \\
\text { ler with DC motor actuators [19] }\end{array}$ & $\begin{array}{l}680 \text { set point } \\
2.9 \% \text { error } \\
2.8 \mathrm{~s} \text { response time } \\
\end{array}$ \\
\hline 4 & $\begin{array}{l}\text { Fuzzified-PID Methods on gun-barrel motion con- } \\
\text { trol with servo motor actuator [20] }\end{array}$ & $\begin{array}{l}600 \text { set point } \\
0 \% \text { error } \\
0.460 \text { s response time }\end{array}$ \\
\hline 5 & $\begin{array}{l}\text { Target tracking S-60 PID-Fuzzy controller with } \\
\text { DC motors [21] }\end{array}$ & $\begin{array}{l}600 \text { set point } \\
0 \% \text { error } \\
0.9 \text { s response time }\end{array}$ \\
\hline 6 & Proposed System & $\begin{array}{l}980 \text { set point } \\
24 \% \text { overshoot } \\
0.052 \text { s response time }\end{array}$ \\
\hline
\end{tabular}


A frame difference image-processing algorithm was examined in terms of detection and tracking of a moving target. It gives a response time of $1.75 \mathrm{~s}$, but with some detection inaccuracy.

The deployed PI controller gives good correction of the steady-state error minimizing the settling time to $0.052 \mathrm{~s}$ but it subject to an overshoot of $24 \%$.

The integrated helmet is composed of a gyroscope, a webcam, and the protection helmet itself. The MEMS gyroscope sensor helps to report the gunner head position. The webcam captures video frames, which helps to detect target aircraft from every frame. The image processor determines and reports the current target's position that is sent to the actuator motors for positioning (steering) of the barrel to the target aircraft position.

All stated algorithms were tested in a real-time experiment to examine the system performance by using a moving helicopter model as target with a speed of $0.25 \mathrm{~m} / \mathrm{s}$ to see how the gun responds to the target's movement. Arduino microcontroller was chosen to control the motors by receiving inputs from the sensors and continuously checking the current position. While image processing was executed on a PC, which was used in place of firing computers that had a specific purpose of computing the firing parameters with small calculation time. Commanding results were obtained in terms of response time and set point when compared to similar previous works.

\section{References}

[1] CARTER, G.L. Gun Control in the United States: A Reference Handbook. Santa Barbara: ABC-CLIO, 2006. ISBN 978-1-85-109760-9.

[2] SINGH, H., S.S. SAINI, N. KUMAR and V. KARAR. Performance Comparison: Optical and Magnetic Head Tracking. International Journal of IT, Engineering and Applied Sciences Research, 2013, 2(3), pp. 27-32. ISSN 2319-4413.

[3] RASH, C.E. (ed.). Helmet-Mounted Displays: Sensation, Perception and Cognitive Issues. Fort Rucker: U.S. Army Aeromedical Research Laboratory, 2009. ISBN 978-0-61-528375-3.

[4] KORAN, F., A. KNIZEK and M. BURIAN. Present Vehicle Line No.6: Gaz-66 Variants in Detail. Wings \& Wheels Publications, 2002. ISBN 978-8-08-641620-5.

[5] KUCUK, S. and Z. BINGUL. Robot Kinematics: Forward and Inverse Kinematics. In: CUBERO, S. ed. Industrial Robotics: Theory, Modelling and Control. Augsburg: Pro Literatur Verlag, 2006, pp. 117-148. ISBN 3-86611-285-8.

[6] RASH, C.E., W.E. McLEAN, J.C. MORA, M.H. LEDFORD and B.T. MOZO. Design Issues for Helmet-Mounted Display Systems for Rotary-Wing Aviation [online]. Defense Technical Information Center, 1998. [viewed 2019-12-16]. Available from: https://www.usaarl.army.mil/TechReports/98-32.PDF

[7] IQBAL, J., A. UL HAQ and S. WALI. Moving Target Detection and Tracking. Saarbrücken: LAP LAMBERT Academic Publishing, 2015. ISBN 978-3-65969832-3.

[8] BALAJI, S.R. and S. KARTHIKEYAN. A Survey on Moving Object Tracking Using Image Processing. In: Proceedings of the $11^{\text {th }}$ International Conference on Intelligent Systems and Control (ISCO). Coimbatore: IEEE, 2017, pp. 469-474. DOI 10.1109/ISCO.2017.7856037. 
[9] PATHAN, I. and C. CHAUHAN. A Survey on Moving Object Detection and Tracking Methods. International Journal of Computer Science and Information Technologies, 2015, 6(6), pp. 5212-5215. ISSN 0975-9646.

[10] BALA, R. and K.M. BRAUN. Color-to-Grayscale Conversion to Maintain Discriminability. In: Proceedings of the SPIE 5293, Color Imaging IX: Processing, Hardcopy, and Applications. San Jose, 2003. DOI 10.1117/12.532192.

[11] SARAVANAN, C. Color Image to Grayscale Image Conversion. In: Proceedings of the International Conference on Computer Engineering and Applications. Bali Island: IEEE, 2010, pp. 196-199. DOI 10.1109/ICCEA.2010.192.

[12] ZHANG, Y, X. WANG and B. QU. Three-Frame Difference Algorithm Research Based on Mathematical Morphology. Procedia Engineering, 2012, 29, pp. 2705-2709. DOI 10.1016/j.proeng.2012.01.376.

[13] HUSSAIN, Z., A. NAAZ and N. UDDIN. Moving Object Detection Based on Background Subtraction and Frame Differencing Technique. International Journal of Advanced Research in Computer and Communication Engineering, 2016, 5(5), pp. 817-819. DOI 10.17148/IJARCCE.2016.55200.

[14] PARIDA, S., W.P. WACHS and M.E. CABRERA. Dynamic Surgical Tool Tracking and Delivery System Using Baxter Robot. In: Proceedings of the Summer Undergraduate Research Fellowship (SURF) Symposium. West Lafayette, 2014, paper 51.

[15] CHAUHAN, B.S., M. SINGH, V.K. SHARMA and P.C. PANDEY. Auto-Video Tracking System: Performance Evaluation. Defence Science Journal, 2008, 58(4), p. 565-572. DOI 10.14429/dsj.58.1678.

[16] MINGQIANG, Y., K. KIDIYO, and R. JOSEPH. A Survey of Shape Feature Extraction Techniques. In: YIN, P.-Y. ed. Pattern Recognition Techniques, Technology and Applications. InTech, 2008, pp. 43-90. ISBN 978-953-7619-24-4.

[17] RAHMAT, M.S., K. HUDHA, A.M. IDRIS and N.H. AMER. Sliding Mode Control of Target Tracking System for Two Degrees of Freedom Gun Turret Model. Advances in Military Technology, 2016, 11(1), pp. 13-28. DOI 10.3849/aimt.01087.

[18] KUSWADI, S., N.M. TAMARA and H.W. DWI NUGROHO. Gun Turret Automatic Weapon Control System Design and Realization. In: Proceeding of the 2016 International Symposium on Electronics and Smart Devices (ISESD). Bandung: IEEE, 2016. DOI 10.1109/ISESD.2016.7886687.

[19] MUSLIM, M.A., D. MINGGU, J. SAPUTRA and R.N. HASANAH. Comparison Analysis between Fuzzy and Fuzzified-Pid Methods on Gun-Barrel Motion Control. Journal of Engineering and Applied Sciences, 2015, 10(20), pp. 9765-9771. ISSN 1819-6608.

[20] SIQQI, M.S., D.S. PURNOMO and I.A. SULISTIJONO. Coil-gun Turret Control System by Using Digital Compass on Helmet. EEPIS Final Project [online]. [viewed 2019-11-02]. Available from: https://core.ac.uk/download/pdf/12344379.pdf

[21] SAPUTRA, J., R.N. HASANAH and M.A. MUSLIM. Target Tracking of the S-60 Single-Barrel 57mm Anti-Aircraft Gun System Using Hybrid Control Method. Journal of Engineering and Applied Sciences, 2015, 10(19) pp. 9071-9077. ISSN 1819-6608. 